\title{
PERANCANGAN IKLAN LAYANAN MASYARAKAT DAMPAK NEGATIF PENGGUNAAN HANDPHONE SAAT BERKENDARA DI KOTA MEDAN
}

\author{
Titin Setiawati ${ }^{1}$, Sofiah Lubis ${ }^{2}$ \\ Prodi Desain Komunikasi Visual Fakultas Seni dan Desain Universitas Potensi Utama \\ titianmee@gmail.com, sofiah286@gmail.com
}

\begin{abstract}
ABSTRAK
Kemajuan teknologi informasi dan komunikasi telah banyak kita rasakan manfaatnya. Handphone adalah suatu alat elektronik untuk saling berkomunikasi dua arah dengan bentuk kecil dan simple sehingga mudah digenggam serta mempunyai kemampuan dalam mengirimkan suatu informasi dalam bentuk teks, suara, gambar maupun video. Akan tetapi dengan adanya kemudahan tersebut orang-orang yang berkendara tidak melihat keselamatan dirinya sendiri, karena mereka sebagian besar menggunakan handphone saat berkendara. Oleh karena itu kita akan membuat sebuah iklan layanan masyarakat untuk menyadarkan atau mempengaruhi orang-orang yang sedang berkendara akan tetapi mereka tidak melihat keselamatan dirinya sendiri. Iklan layanan masyarakat ini mempunyai media utama yaitu sebuah poster. Poster merupakan media cetak yang mana didalamnya terdapat huruf dan gambar dengan media kanvas kertas, albatros dan lainnya mulai dari ukuran kecil hingga besar. Dengan pengaplikasiannya ditempel pada seluruh tempat yang bisa mencari perhatian mata sekuat mungkin, agar masyarakat sadar akan keselamatan didalam berkendara.
\end{abstract}

Kata Kunci : Iklan Layanan Masyarakat, Dampak Handphone, Berkendara

\begin{abstract}
The progress of information and communication technology has many benefits. Mobile is an electronic device for copying two-way communication with a small and simple form so that it is easily grasped and has the ability to send information in the form of text, sound, images and videos. However, with this convenience, people who drive do not see their own safety, because they mostly use cellphones when driving. Therefore we will make a public service advertisement to make people aware or influence those who are driving, but they do not see their own safety. This public service ad has the main media, namely a poster. Poster is a print media which includes letters and pictures with paper canvas media, albatros and others ranging from small to large sizes. With the application affixed to all places that can look for eye attention as strong as possible, so that people are aware of driving safety.
\end{abstract}

Keywords : Public Service Announcements, Mobile Phone Impact, Drive

\section{PENDAHULUAN}

Perkembangan teknologi informasi dan komunikasi yang kita rasakan saat ini tentunya sangat membantu kita dalam berkomunikasi. Salah satu teknologi tersebut adalah Smartphone, jadi dengan adanya handphone yang semakin canggih di era 
sekarang ini kita sebagai pengguna sering tidak memperhatikan keselamatan diri kita sendiri. Banyaknya kecelakaan sebagian besar terjadi dikarenakan berkendara sambil menggunakan handphone. Penjelasan umum Peraturan Perundang-undangan Nomor 22 Tahun 2009 menerangkan bahwa lalu lintas dan angkutan jalan adalah satu kesatuan system yang terdiri atas lalu lintas, angkutan jalan, jaringan lalu lintas dan angkutan jalan, prasarana lalu lintas dan angkutan jalan, kendaraan, pengemudi, pengguna jalan, serta pengelolaannya. Jalan raya memiliki peran sangat penting dalam kehidupan berlalu lintas, sebab sebagian besar kegiatan sehari hari manusia selalu menggunakan lalu lintas pada jalan raya baik dalam bidang ekonomi, politik, sosial, hukum dan bidang lainnya. Jalan raya juga berfungsi sebagai sarana yang memungkinkan setiap manusia dapat saling berhubungan. Sejak lahir di dunia, manusia sudah berhubungan dengan orang tuanya misalnya, dan semakin meningkat usianya, bertambah luas pulalah pergaulannya dengan manusia lain dimasyarakat.

Semakin luas pergaulan maka akan menghasilkan sebuah mobilitas yang lebih luas juga, apabila mobilitas dan arus lalu lintas suatu daerah, maka jalan raya yang digunakan juga akan semakin besar juga. Satoshi Kanazawa, seorang evolutionary psychologist berpendapat bahwa manusia didesain memiliki pola pikir untuk berkomunikasi secara wajar dengan saling menatap lawan komunikasi, ketika manusia melakukan dua atau lebih pekerjaa maka akan kurang konsentrasi dan fokus terpecah, seperti mengemudi sambil menelpon. Tidak bisa/ dipungkiri kesibukan masyarakat pada saat sekarang ini memang sangat terasa, oleh karena itu keberadaan handphone sudah tidak dapat dipisahkan lagi, tapi apabila hal ini dilakukan ketika berkendara maka hal yang membahayakan akan terjadi, seperti kecelakaan berlalu lintas.

Jumlah kecelakaan saat berkendara dikota medan semakin meningkat bahkan sampai meninggal dunia. Oleh sebab itu untuk mengurangi kecelakaan yang disebabkan oleh handphone pada saat berkendara maka dibuatlah sebuah Perancangan Iklan Layanan Masyarakat Dampak Negatif Penggunaan Handphone Saat Berkendara, agar orang-orang yang berkendara lebih memperhatikan keselamatan dirinya sendiri. Dengan adanya ILM ini akan mempengaruhi mindset pengendara untuk tidak menggunakan handphone saat dijalan raya, khusunya warga kota medan. Dengan adanya iklan layanan masyarakat yang nantinya akan dibuat disetiap jalan kota medan akan membuat masyarakat menyadari akan pentingnya keselamatan disaat berkendara.

\section{STUDI LITERATUR}

\section{II.1. IKLAN LAYANAN MASYARAKAT}

Menurut kasali (1992:136) Iklan Layanan Masyarakat merupakan jenis iklan yang digunakan dalam menggerakan pola pikir dan perasaan masyarakat manakala menghadapi suatu masalah dalam kehidupan bersosial. Dalam iklan layanan masyarakat tersebut disajikan pesan dan informasi sosial untuk menumbuhkan kepedulian masyarakat dalam beberapa masalah yang dihadapi seperti kondisi yang dapat mengancam keharmonisan dan kehidupan masyarakat. Iklan Layanan Masyarakat juga salah satu cara untuk mengajak dan menghimbau masyarakat agar mereka paham dan sadar akan pesan yang di muat pada iklan tersebut. Jadi dapat disimpulkan bahwa iklan layanan masyarakat merupakan alat untuk memberikan informasi kepada masyarakat 
dalam hidup bersosial, dan prosedur pembuatannya mengacu pada pembuatan iklan komersial.

Jadi kaitan dengan perancangan yang akan dibuat adalah, untuk memberikan informasi dan pesan agar para pelajar dan mahasiswa serta masyarakat bisa mengubah kebiasaan dan perilaku masyarakat yang negatif serta dapat melakukan suatu aksi untuk kepentingan bersama.

Iklan Layanan Masyarakat (ILM) memiliki sifat nonprofit yaitu merupakan pemasanganya tidak untuk mendapatkan keuntungan uang namun hanya untuk kepentingan masyarakat umum. (Liliweri, 31 : 1992). Sedangkan menurut Kasali (1995 : 201) "Iklan Layanan Masyarakat adalah suatu jenis iklan yang dibuat dengan biaya yang tidak besar dan tidak komersial yang bertujuan untuk mempromosikan program program ; kegiatan - kegiatan yang diadakan oleh pemerintah atau digunakan oleh organisasi - organisasi kemasyarakatan yang non profit dan sebagai iklan yang berfungsi untuk kepentingan masayarakat, tidak termasuk acara prakiraan cuaca dan iklan promosi produk".

\section{II.2. DAMPAK BERKENDARA}

Di era sekarang ini masyarakat tidak bisa lagi terlepas dari sebuah handphone karena handphone sudah dianggap sebagai kebutuhan pokok masyarakat dalam berkomunikasi bahkan sebagai sumber berbagai informasi. Akan tetapi masyarakat tidak menyadari akan keselamatan untuk dirinya, mereka beranggapan bisa menggunakan handphone tersebut dimana pun mereka berada termasuk didalam perjalanan. Karena menggunakan handphone dalam berkendara sangatlah berdampak negatif bagi pengendara, hal tersebut dapat mengakibatkan kecelakaan bahkan bisa menyebabkan kematian. Oleh karena itu penulis akan membuat sebuah iklan layanan masyarakat untuk merubah pola pikir masyarakat ketika berkendara dengan menggunakan handphone.

Menggunakan ponsel saat mengendarai pada dasarnya melanggar dua pasal yang terdapat pada Undang-Undang No. 22 tahun 2009 mengenai Lalu-Lintas serta Angkutan Jalan, yakni pasal 106 yang mewajibkan pengemudi berkendara dengan wajar dan penuh konsentrasi, serta pasal 283 yang mengatur pidana kurungan paling lama 3 (tiga) bulan dan denda paling banyak 750.000 rupiah bagi para pelanggar.

\section{PEMBAHASAN}

\section{III.I. METODE PERANCANGAN}

Berdasarkan data dan informasi yang telah diperoleh, maka agar tahapan dan proses perancangan iklan layanan masyarakat dampak negatif penggunaan handphone saat berkendara di kota medan ini lebih mudah dan sistematis maka diperlukan penyusunan metode, strategi, struktrur dalam perancangan yang akan digarap.

\section{A. Ruang Lingkup Perancangan}


Agar pembahasan dalam perancangan ini tidak meluas dan agar tidak mengurangi tujuan yang ingin dicapai, maka perlu adanya pembatas ruang lingkup di dalam perancangan kampanye social ini, dimana target audience dalam perancangan ini adalah masyarakat. Kedua target tersebut dengan segmentasi sebagai berikut :

1. Demografi

Usia

: 15 Tahun Keatas (target audience)

: Para Remaja, Orangtua, dan Masyarakat

Jenis Kelamin : Laki-laki dan Perempuan

2. Geografi

Lokasi yang dituju adalah Kota Medan Sumatera Utara, akan tetapi tidak menuntut kemungkinan akan digunakan untuk kota lainnya.

3. Psikograf

Didalam iklan layanan masyarakat ini yang menjadi target audience adalah remaja, orangtua, dan masyarakat.

\section{B. Metode Pengumpulan Data}

\section{Data Visual}

a. Dokumentasi

Mencari sumber informasi berupa foto, dokumen dan data tentang berkendara dengan aman di kota medan. Selain itu, proses dokumentasi juga langsung menuju ke lapangan.

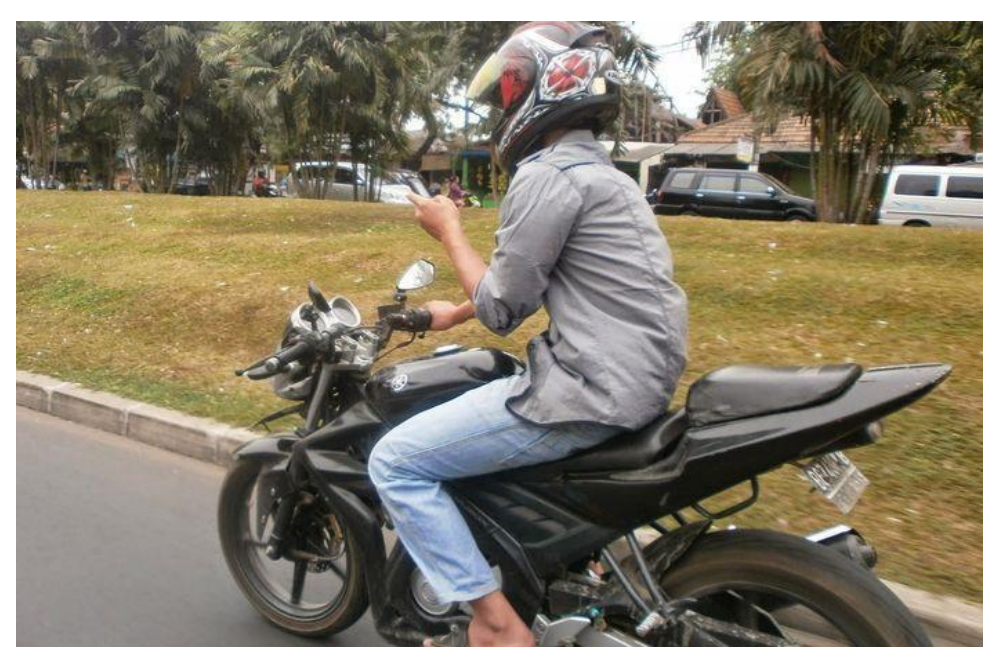

Gambar 1. Berkendara Sambil SMS 


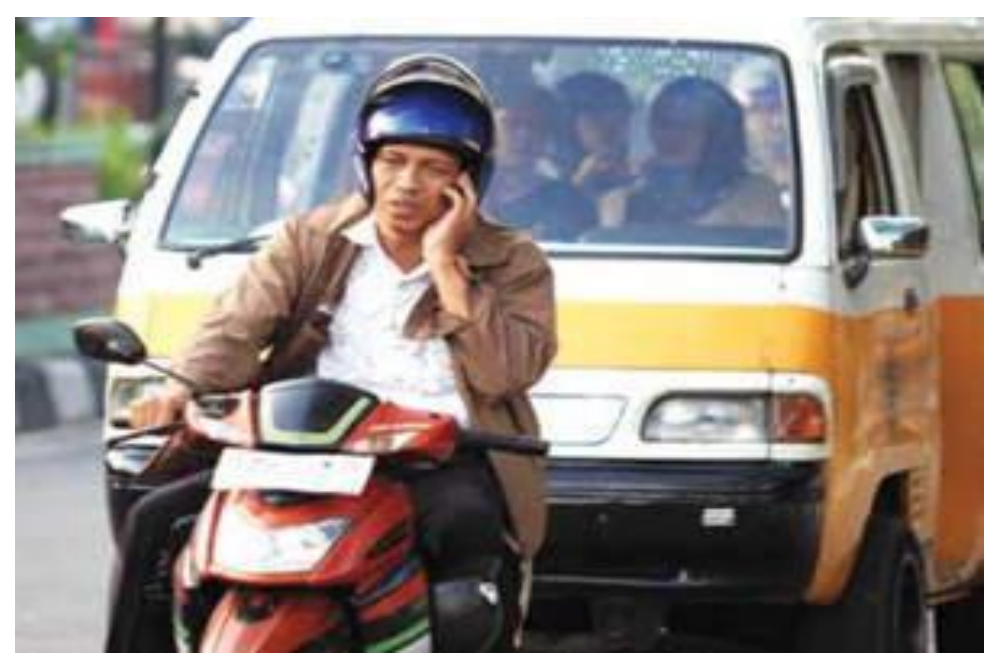

Gambar 2. Berkendara Sambil Angkat Handphone

b. Kepustakaan

Data visual yang diperlukan dalam perancangan juga diperoleh dari berbagai sumber kepustakaan seperti buku, jurnal, dan lain lain.

\section{c. Website}

Selain dokumentasi dan kepustakaan, pengambilan data visual juga ditunjang dari gambar-gambar yang ada di website. Pengambilan data visual di website bertujuan untuk mempermudah data-data yang sulit untuk di dokumentasikan sendiri serta untuk memenuhi kebutuhan bentuk visual pada perancangan yang tidak diperboleh dari dokumentasi sendiri.

\section{Data Verbal}

a. Wawancara

Penulis akan melakukan wawancara dengan bertanya kepada beberapa sumber, yaitu orang-orang yang dapat memberikan informasi untuk melengkapi data dalam perancangan ini. Metode wawancara yang akan dilakukan adalah metode wawancara terstruktur (Structured Interview) dan wawancara tidak terstruktur (Unstructured Interview) wawancara terstruktur dilaksanakan dengan mempersiapkan terlebih dahulu pertanyaan yang ingin di ajukan dan wawancara tidak terstuktur adalah wawancara bebas tanpa membuat daftar pertanyaan.

b. Observasi

Observasi dilakukan dengan terjun langsung kelapangan mengunjungi jalan jalan raya yang ada di kota medan untuk mendapatkan data dan informasi yang diperlukan dalam perancangan ini

\section{Identifikasi Data}

a. Sebagian besar masyarakat yang menggunakan telepon saat berkendara adalah remaja dan orang orang dewasa usia 15 keatas

b. Menggunakan telepon saat berkendara mengakibatkan dampak buruk diantaranya:

1) Melanggar dua pasal undang-undang 
2) Menyebabkan terjadinya kecelakaan

3) Mengurangi konsentrasi dan kewaspadaan saat berkendara

\section{Analisa Data}

Metode analisis data yang digunakan dalam pemecahan masalah perancangan ini adalah dengan metode $5 \mathrm{~W}+1 \mathrm{H}$ yang akan membahas mengenai spesifikasi perancangan karya.

-What : Perancangan kampanye sosial dampak negatif penggunaan handphone saat berkendara.

- Where : Kota Medan.

- When : Saat ini dan dimasa yang akan datang.

- Who : Anak remaja, orangtua dan masyarakat.

- Why : Karena masih kurangnya kesadaran masyarakat dalam berkendara

dan untuk mengurangi kecelakaan berkendara

- How : Dalam hal ini perancang akan membuat iklan

Layanan masyarakat dalam bentuk : poster atau spanduk.

\section{III.2. VISUALISASI}

\section{Konsep Kreatif}

Untuk Iklan layanan masyarakat dengan tema yaitu "Dampak menggunakan telepon saat berkendara" ada tiga ide besar yang akan dijadikan sebagai pijakan dalam perancangannya. Ide tersebut adalah sebagi berikut:

a. "Kecelakaan"

Gambar kecelakaan yang ada pada desain ILM ini akan digambarkan sebuah kecelakaan yang diakibatkan penggunaan telepon saat berkendara yang terlihat cukup berbahaya sehingga yang melihat akan merasakan efeknya dan menjauhi hal tersebut.

b. "Berhenti Mempertaruhkan Nyawamu"

Tagline ini untuk menyadarkan seluruh masyarakat untuk tidak mempertaruhkan nyawa mereka dengan menggunakan handphone saat berkendara karena dapat menyebabkan kecelakaan yang merugikan diri sendiri dan orang lain tentunya.

c. "Palu Jaksa"

Gambar palu jaksa yang ada pada desain ILM ini akan di buat dengan label "Pasal UUD" dan palu yang akan memukul seorang pengendara yang sedang berkedar sambal menggunakan handphone, agar para audience tahu bahwa menggunakan handphone saat berkendara adalah melanggar hukum yaitu melanggar pasal Undang Undang.

Ketiga ide besar diatas akan diwujudkan beberapa ke dalam bentuk visual yang menarik agar bisa menarik perhatian target audience, dan diaplikasikan ke dalam media publikasi, seperti poster. 


\section{SKETSA MANUAL}
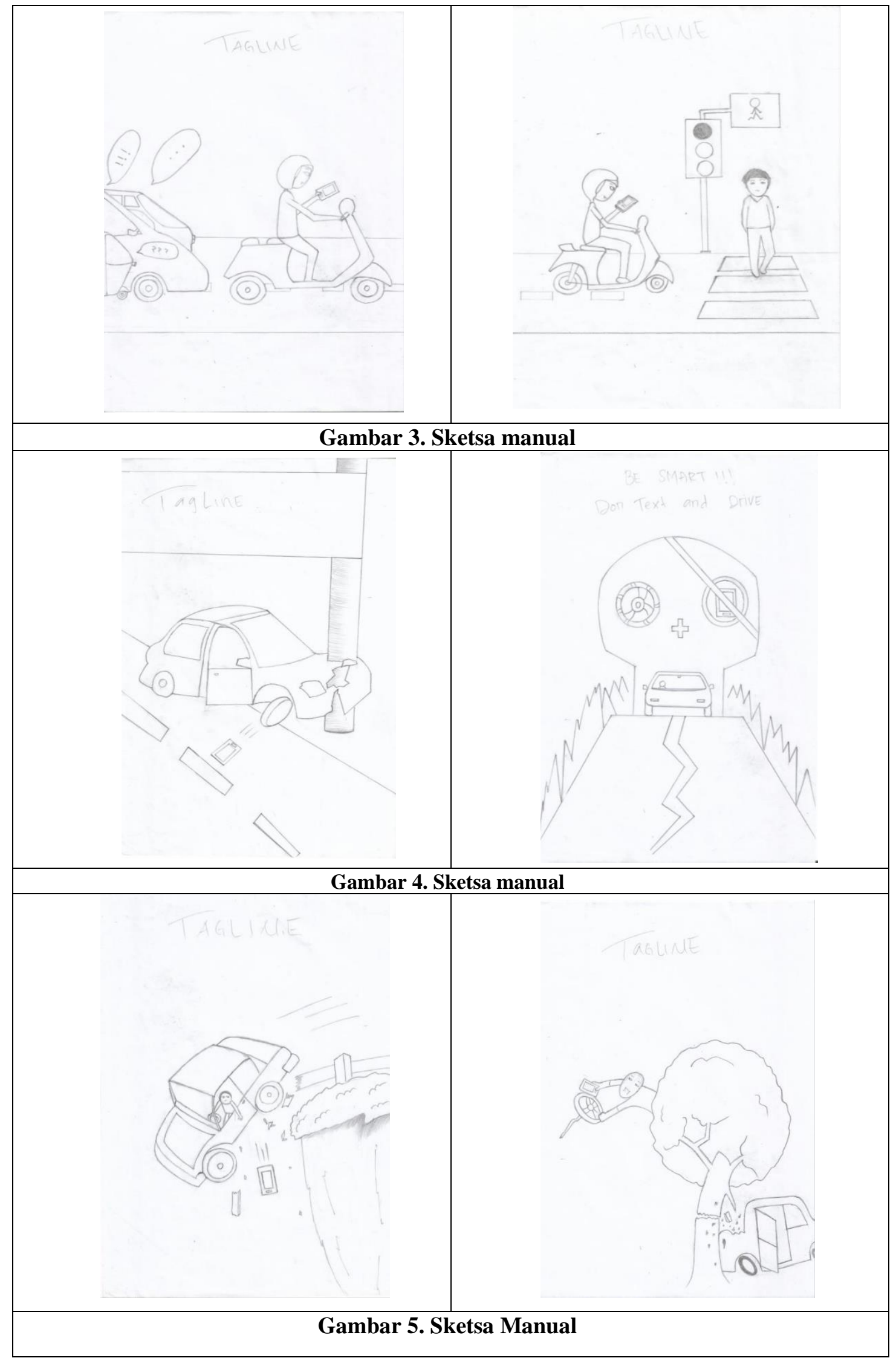


\section{SKETSA TERPILIH}

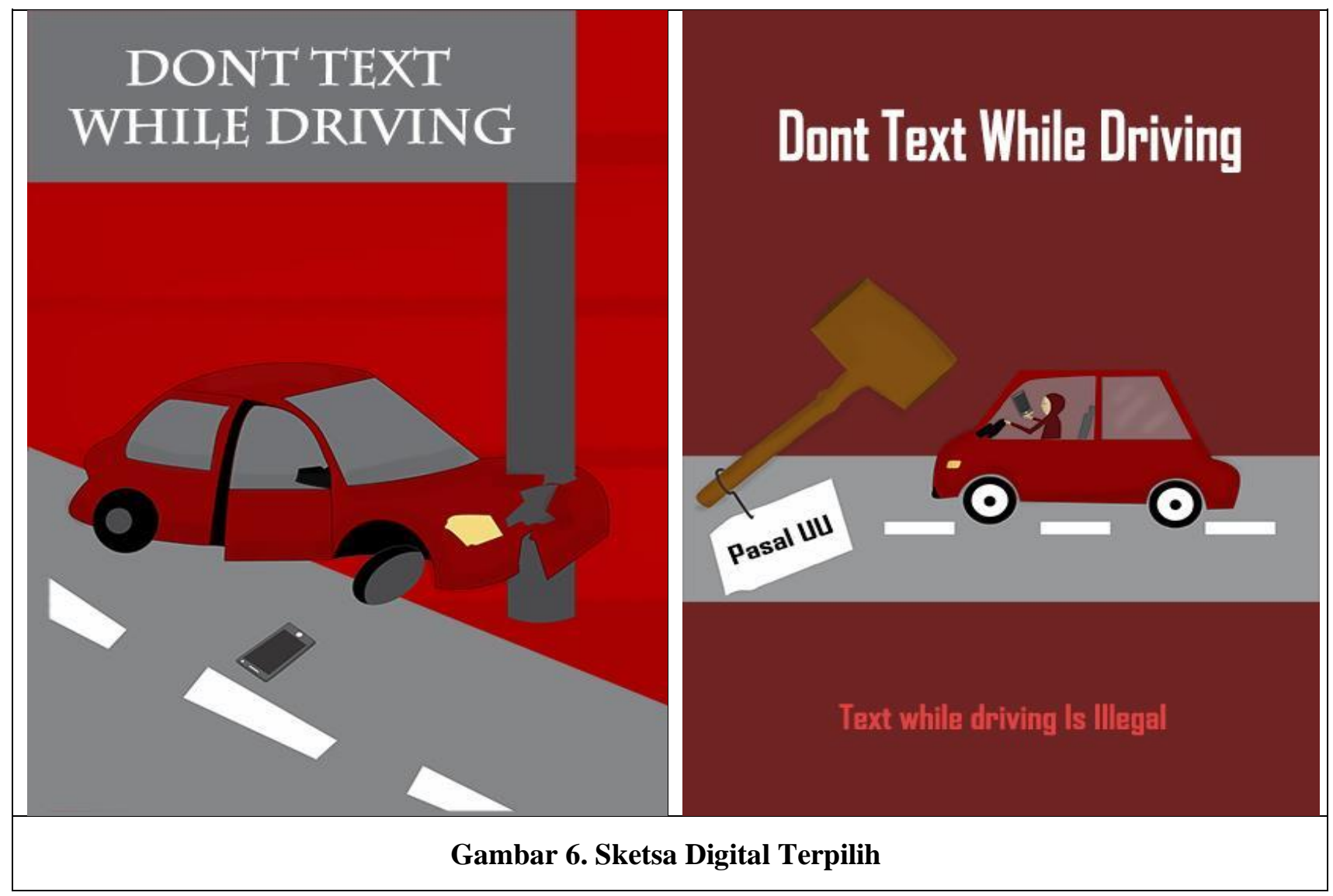

\section{Dont Text While Driving}

\section{DONT TEXT WHILE DRIVING}
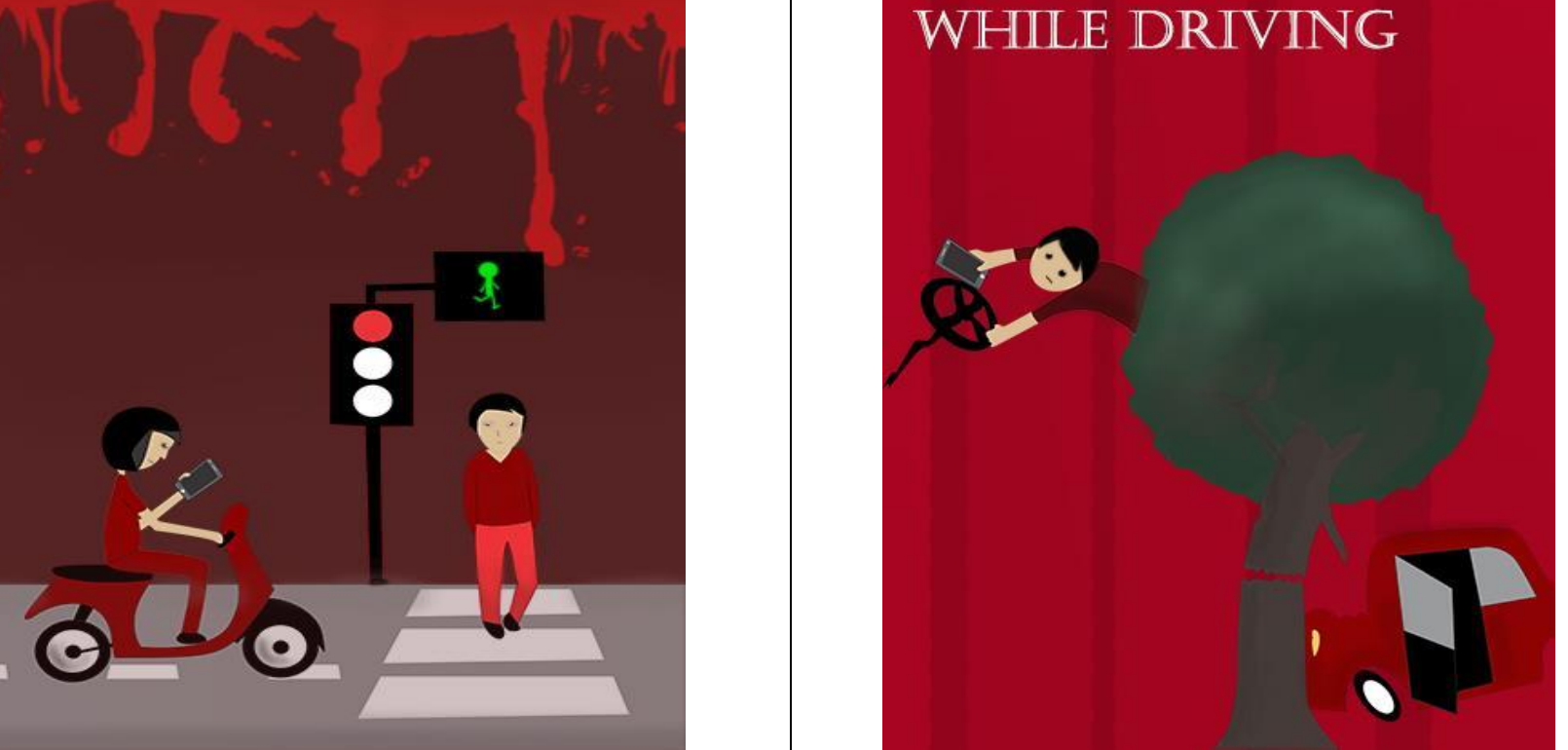

Gambar 7. Sketsa Digital Terpilih 


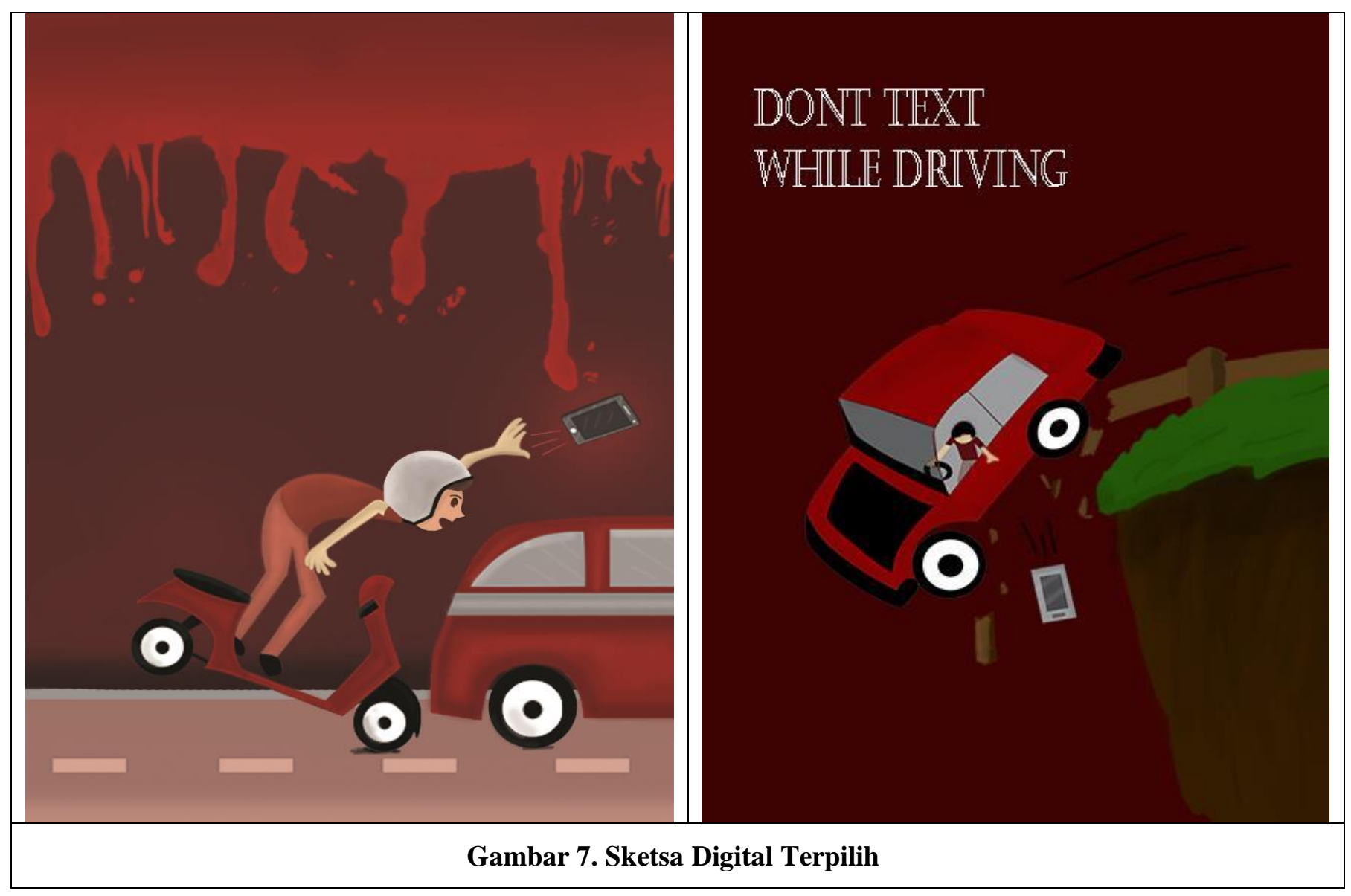

4. FINAL DESAIN

\section{Berhenti mempertaruhkan nyawamu!}

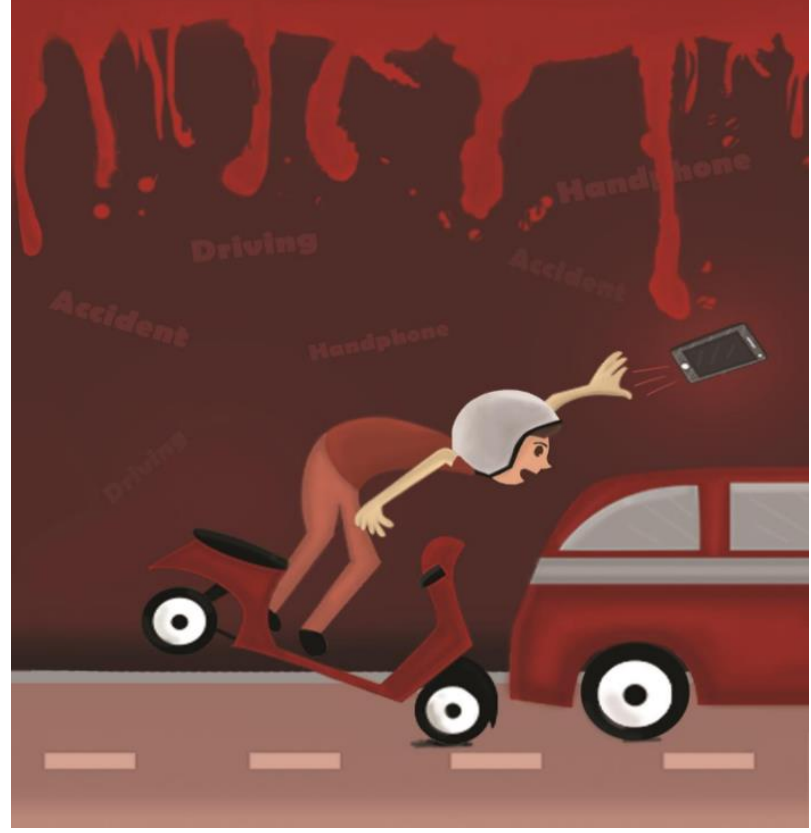

Gambar 8. Final Desain ILM dampak negative penggunaan handphone saat berkendara 


\section{PENUTUP}

Kesibukan masyarakat pada saat sekarang ini dengan keberadaan telepon genggam sudah tidak dapat dipisahkan lagi, tapi apabila hal ini dilakukan ketika berkendara maka hal yang membahayakan akan terjadi, contohnya kecelakaan. Dari hasil Iklan Layanan Masyarakat diatas diharapkan dapat meningkatkan kesadaran masyarakat akan keselamatan berkendara. Mengingat tingginya tingkat kecelakaan yang ada pada kota medan, dengan adanya iklan layanan masyarakat ini akan meminimalisir tingkat kecelakaan yang ada pada kota medan. Sebaiknya disaat berkendara kita tidak melakukan hal tersebut.

\section{DAFTAR PUSTAKA}

[1] Alo Liliweri. (1992). Dasar - dasar Komunikasi Periklanan. Bandung: Citra Aditya Bakti.

[2] Archer, L. B.(1965). Systematic Method For Designers. The Design Council Designers.

[3] Kasali, Rhenald. (1992). Iklan Layanan Masyarakat. Jakarta: Pustaka Utama Grafiti.

[4] Sachri, Agus. (2005). Defenisi Desain. Yogyakarta: Andi. 